\title{
Effect of Exercise Training on Bcl-2 and Bax Gene Expression in the Rat Heart
}

\author{
Afshar Jafari, ${ }^{1}$ Hassan Pourrazi, ${ }^{1, *}$ Saeid Nikookheslat, ${ }^{1}$ and Behzad Baradaran ${ }^{2}$ \\ ${ }^{1}$ Department of Exercise Physiology, Tabriz University, Tabriz, IR Iran \\ ${ }^{2}$ Department of Immunology, Tabriz University of Medical Sciences, Tabriz, IR Iran \\ *Corresponding author: Hassan Pourrazi, Department of Exercise Physiology, Tabriz University, Tabriz, IR Iran. Tel:+98-4133393258, Fax: +98-4133393257, E-mail: purrazi.h@gmail.com
}

Received 2015 August 31; Revised 2015 October 19; Accepted 2015 October 20.

\begin{abstract}
Background: Apoptosis or programmed cell death plays an important role in the development of cardiovascular diseases, particularly heart failure. Current evidence suggests that exercise training may alter apoptosis-related signaling in sensitive somatic tissues such as the myocardium.

Objectives: The aim of this study was to assess the effect of exercise training on Bcl-2 and Bax genes expression as key molecules involved in intrinsic pathway of apoptosis in the rat heart.

Materials and Methods: This study was conducted with a two-group experimental design (animal model) and sixteen three-month-old male rats were selected and randomly divided to two groups of exercise training $(n=8)$ and control $(n=8)$. Rats in the trained group participated in an exercise training program for 12 weeks (10 - $\left.60 \mathrm{~m} \mathrm{~min}^{-1}, 24-33 \mathrm{~min}^{-1}, 15 \%\right)$. The rat hearts were removed forty-eight hours after the last training session. RNA extraction and synthesis of cDNA was done, and Bax and Bcl2 genes expression was analyzed through the Real Time-Polymerase Chain Reaction (RT-PCR). Kolmogorov-Smirnov and independent t-test were applied for statistical analysis of the data $(\mathrm{P}<0.05)$.

Results: The results showed that Bax gene expression and Bax/Bcl2 ratio of the trained group were significantly lower than the control group, $81 \%$ and $89 \%$, respectively $(\mathrm{P}<0.05)$. Moreover, there was no significant difference between the two groups in $\mathrm{Bcl} 2(\mathrm{P}>0.05)$. However, Bcl2 expression was higher in the trained group compared to the control group (11\%).

Conclusions: In general, it seems that three-month exercise training was effective in reducing cardiac mitochondrial pro-apoptotic protein. However, considering the results of the Bcl2 gene expression, more researches are needed to identify effects of exercise trainings on indices of myocardial apoptosis.
\end{abstract}

Keywords: Exercise, Myocardium, Apoptosis

\section{Background}

Apoptosis is a highly organized and tightly coordinated biological process that plays a vital role in monitoring a variety of non-pathological cellular events (e.g.tissue turnover). Several distinctive morphological characteristics define apoptosis, including cell shrinkage, plasma membrane blebbing, chromatin condensation, degradation of chromosomal DNA at inter-nucleosomal intervals, and formation of apoptotic bodies (1-3). Although apoptosis is important in regulating cell proliferation and removal of precancerous cells in adult mitotic tissues (e.g. the heart, liver and kidneys), deregulation of apoptosis is now recognized as a mechanism fundamental to numerous pathologies $(1,4)$. Apoptosis is very rare in normal myocardium with a reported rate of $0.001-0.002 \%$, however it is increased in both acute and chronic heart pathologies, where it seems to play an important role (1). Apoptotic signaling induces apoptosis, primarily through three types of complex pathways. They include:1) cytokine/Fas receptordriven pathway, 2) mitochondrial-driven pathway, and 3 ) endoplasmic reticulum $/ \mathrm{Ca}^{2+}$-driven pathway $(2,5-8)$.
Among them, mitochondrial-mediated pathway, including the Bcl-2 family is the best characterized and believed to be critical in regulating apoptosis (7-9). The molecular events that result in the activation and subsequent execution of the apoptotic program are principally controlled by the balance between pro- and anti-apoptotic signaling, and this is primarily determined by specific apoptotic regulatory proteins. The B-cell leukemia/lymphoma-2 (Bcl2) family of upstream regulators of apoptosis includes crucial intracellular checkpoint proteins in the apoptotic signaling pathway. The Bcl-2 family members, Bcl-2 associated X (Bax) protein and Bcl-2, have been identified as putative key proteins involved in the formation of mitochondrial apoptotic channels and also in the regulation of mitochondria permeability and mitochondrial-associated apoptotic signaling (2, 5-7, 10). Furthermore, Bax has been shown to translocate to the mitochondria and expose its $\mathrm{NH}_{2}$ terminus via a conformational change on induction of apoptosis. This conformational change permits Bax-Baxoligomerization and insertion of Bax into the outer mito-

Copyright (C) 2015, Zahedan University of Medical Sciences. This is an open-access article distributed under the terms of the Creative Commons Attribution-NonCommercial 4.0 International License (http://creativecommons.org/licenses/by-nc/4.0/) which permits copy and redistribute the material just in noncommercial usages, provided the original work is properly cited. 
chondrial membrane, which is followed by the rapid release of apoptogenic factors (e.g., cytochrome c) from the mitochondrial intermembrane space $(1,2,7)$. Collectively, Bax oligomerization is thought to be critical for mitochondrial membrane permeabilization, whereas Bcl-2 opposes the proapoptotic activity of Bax by preventing Bax-Bax oligomerization. In between, although different initiator caspases are recruited in different apoptotic pathways, it appears that the apoptotic signals finally converge on the activation of the common effector caspases (e.g. caspase-3 and -7), which cause eventual destruction of the cell (1, 2). Therefore, developing a strategy to protect the heart against apoptosis-mediated damage is important. In the recent years, the impact of different exercises and training on apoptosis has gained the interest of many exercise scientists and researchers, because, in addition to necrotic cell death, evidence indicates that apoptotic cell death also occurs with exercise. However, during the last decade, a number of researchers have reported that regular and moderate exercise training is able to decrease the level of apoptosis in adult healthy postmitotic tissues (3, 10-12). Unfortunately, the results of these studies are also conflicting in some cases. In this regard, Peterson et al. found that nine weeks of moderate exercise training could reduce the Bax protein levels, caspase activity and DNA fragmentation in cardiac tissue of obese Zucker rats (7). These findings were supported by Quindry et al., who showed that treadmill training up-regulated antiapoptotic markers in the cardiac tissue of rats after Ischemia Reperfusion (IR) injury (8). However, unlike the results of these studies, Xin et al. showed that long-term endurance exercise can change cardiac Bcl-2 and Bax mRNA expression, and induce cardiac apoptosis by oxidative stress (13). Therefore, research is needed to investigate alterations in pro and anti-apoptotic proteins during long-term endurance training especially in elite endurance athletes. Alterations in these death/ survival proteins may possibly explain how exercise training partly prevents the loss of cardiac cells or how longterm and strenuous exercise training partly promotes the apoptosis of cardiac cells. Moreover, improving our understanding about the molecular basis for exercise-induced cardio-protection will play an important role in developing optimal exercise training interventions for primary and secondary prophylaxis.

\section{Objectives}

The purpose of the present study was to determine the effect of three-month exercise training on Bcl-2 and Bax gene expression in rat hearts.

\section{Materials and Methods}

\subsection{Animals}

An experimental design was employed for this study and all experimental procedures were performed ac- cording to the guidelines of the Helsinki declaration and approved by the Regional Research Ethics Committee of Tabriz University of Medical Sciences. Sixteen male Wistar rats (Rattus Norvegicus, two-month-old) were obtained from the Pasteur Institute of Tehran, Iran. The rats were housed in pathogen-free conditions at $22 \pm 2^{\circ} \mathrm{C}$, with a relative humidity of $50 \pm 10 \%$ for 14 days. They were exposed to a reverse light condition of 12 hours of light and 12 hours of darkness each day and were fed rat chow and water ad libitum throughout the study period.

\subsection{Exercise Training Protocol}

All animals were familiarized with walking on a motor-driven treadmill $\left(0 \%, 10-15 \mathrm{~m} \mathrm{~min}^{-1}, 5-10 \mathrm{~min} \mathrm{~d}^{-1}\right)$ daily for 14 days. At the end of this period, animals were weight matched and randomly assigned to either a sedentary control $(\mathrm{N}=8)$ or an endurance exercise-trained group $(\mathrm{N}=8)$. The treadmill training program was designed using the oxygen cost of treadmill running data (14). The training consisted of running during the dark period $\left(5 \mathrm{~d} \mathrm{wk}^{-1}\right)$ at relative exercise intensity $(75-80 \%$ VO ${ }^{2 \text { peak }}$ ) during the 12-week training period (Table 1). Electrical shocks were rarely used to motivate the animals to run. Because handling and placing the animals on a treadmill may cause non-exercise stress, sedentary control animals were also placed on the treadmill once a week to familiarize them with handling and the treadmill environment.

\subsection{Tissue Removal}

All trained animals were anesthetized with ketamine (90 $\mathrm{mg} / \mathrm{kg}$, Intraperitoneally (IP)) and xylazine (10 mg/kg, IP) and killed 48 hours after the last training session. Sedentary animals were killed at the same time as their partner trained animals. The cardiac tissues were carefully removed and rinsed in ice-cold physiological saline solution. The left ventricle was removed and frozen immediately in liquid nitrogen and stored at $-70^{\circ} \mathrm{C}$ until further analysis.

\subsection{Isolation of Total RNA}

Fifty milligrams of the left ventricle tissue was homogenized in the presence of $1 \mathrm{~mL}$ of AccuZol $®$ (Bioneer, South Korea). After adding $0.2 \mathrm{~mL}$ chloroform, vigorous shaking and incubation on ice was applied for five minutes. The samples were centrifuged at $13700 \mathrm{~g}$ for 15 minutes at $4^{\circ} \mathrm{C}$. Next, the clear upper phase containing the RNA was transferred to a new tube. An equal volume of cold isopropyl alcohol was added and after inverting the tube four to five times, samples were incubated at $20^{\circ} \mathrm{C}$ for 10 minutes before being centrifuged at 13700 $\mathrm{g}$ for 10 minutes at $4^{\circ} \mathrm{C}$. The supernatant was removed and the pellet was washed in $1 \mathrm{ml}$ of $80 \%$ cold ethanol followed by centrifugation at $13700 \mathrm{~g}$ for five minutes at $4^{\circ} \mathrm{C}$. After removing the supernatant, the pellet was airdried and re-dissolved in Diethylpyrocarbonate (DEPC)- 
treated water. Total RNA concentration and purity of the samples were determined by a Bio-Rad spectrophotometer (Bio-Rad, CA, USA). RNA integrity was verified by ethidium bromide staining of $28 \mathrm{~S}$ and $18 \mathrm{~S}$ ribosomal RNA bands on $1 \%$ agarose gel. After treating RNA with DNAse, extracted RNA was stored at $-70{ }^{\circ} \mathrm{C}$ for further use.

\section{5. cDNA Synthesis}

For this, $1 \mu \mathrm{L}$ of random hexamer primer $\left(2 \mu \mathrm{g} \mu \mathrm{L}^{-1}\right)$ (Fermentas) was added to $2 \mu \mathrm{L}$ of extracted RNA (100 ng $\mu \mathrm{L}^{-1}$ ) and a total volume of $10 \mu \mathrm{L}$ was reached with the addition of DEPC-water. The mixture was incubated at $65^{\circ} \mathrm{C}$ for five minutes and chilled on ice. Next, $4 \mu \mathrm{L}$ of 5 $\times$ reaction buffer, $2 \mu \mathrm{L} 10 \mathrm{mM}$ dNTP mix, $1 \mu \mathrm{L}$ RiboLockTM RNase inhibitor (Fermentas) and $1 \mu \mathrm{L}$ of M-MuLV reverse transcriptase were added followed by incubation at 25 ${ }^{\circ} \mathrm{C}$ for five minutes, at $42^{\circ} \mathrm{C}$ for 50 minutes and finally $72^{\circ} \mathrm{C}$ for five minutes. Finally, a $10-\mu \mathrm{L}$ volume of the cDNA preparation was diluted to increase the total volume of the solution to $100 \mu \mathrm{L}$ and stored at $-20^{\circ} \mathrm{C}$.

\subsection{Real-time Polymerase Chain Reaction and Gene Expression Analysis}

Real-time PCR was carried out using SYBR® Premix Ex Taq $^{\text {TM }}$ II (TAKARA) following the manufacturer's instructions. The mixture comprised of $10 \mu \mathrm{L}$ SYBR green mix, 1.2 $\mu \mathrm{L}$ of cDNA (equivalent to $1.0 \mathrm{ng}$ of total RNA with initial concentration of $\left.100 \mathrm{ng} \mu \mathrm{L}^{-1}\right), 0.4 \mu \mathrm{L}$ PCR forward primers and $0.4 \mu \mathrm{L}$ PCR reverse primer in $10 \mathrm{pmol} \mu \mathrm{L}^{-1}$, and millipore water was added to achieve a final volume of $20 \mu \mathrm{L}$. The sequences of primers are presented in Tables 2. The Threshold Cycle (CT) was determined manually for each run. The PCR efficiencies for each set of primers were determined using serial 10-fold dilutions of cDNA and resulting plots of CT vs. the logarithmic cDNA dilution, using the efficiency equation ( $\mathrm{E}): \mathrm{E}=10^{\text {(-1/slope) }}$. Melting curve analysis was performed for one cycle at $95^{\circ} \mathrm{C}$ for five seconds, $67^{\circ} \mathrm{C}$ for 25 seconds, and $99^{\circ} \mathrm{C}$ for zero second with a ramp rate of $0.1^{\circ} \mathrm{Cs}^{-1}$ and $55^{\circ} \mathrm{C}$ for 30 seconds. The quantification of mRNA was performed as a value relative to an internal reference for $\beta$-actin. Gene expression of the samples compared to the controls was calculated according to the following equation, using the RESTC software 2009.

$$
\text { Ratio }=\frac{\left(e_{\text {target }}\right)^{\Delta \mathrm{c}} \text { Ttarget }(\text { control-sample })}{\left(E_{\beta \text {-avtin }}\right)^{\Delta \mathrm{c}} \operatorname{Ttarget}(\text { control-sample })}
$$

\subsection{Statistical analysis}

All data were expressed as means \pm Standard Error of the Mean (SEM). The Kolmogorov-Smirnov test was used to verify normal statistic distributions. Furthermore, Student's t test was used to examine differences between control and training groups. The level of significance was set at $\mathrm{P}<0.05$. Statistical analyses were carried out using the SPSS software (version 19).

\section{Results}

The Kolmogorov-Smirnov test showed that the data was normally distributed. The results showed that 12-week exercise training reduced body mass by $\sim 11 \%$ in the trained group compared with the control group $(\mathrm{P}<0.01)$. Additionally, the 12 weeks of treadmill exercise increased heart weight by $\sim 5 \%(\mathrm{P}>0.05)$ and increased heart/body weight ratio by $\sim 19 \%(\mathrm{P}<0.01)$ in the trained group compared with the control (Table 3 ).

Regarding Bax and Bcl-2 protein expression, the ability for anti-apoptotic Bcl-2 to inhibit the activity of proapoptotic Bax was dependent not only on the expression levels of these proteins, but also on the ratio of Bax to Bcl-2. The results showed that transcript contents of Bax in ventricle muscles of the trained group decreased by $\sim 81 \%$ when compared with that of the control group $(\mathrm{P}<0.05)$ (Figure 1). Moreover, we found that Bcl-2 protein expression in ventricle muscles of trained animals increased by $11 \%$ when compared with that in the ventricle of control animals, yet the difference did not reach statistical significance $(\mathrm{P}>0.05)$ (Figure 2$)$. Additionally, the myocardial Bax/Bcl-2 ratio was significantly higher $(\mathrm{P}<0.01)$ in the control group compared with the trained group $(\sim 89 \%)$ (Figure 3 ).

Table 1. Details of the Exercise Training Protocol Used in This Study

\begin{tabular}{|c|c|c|c|c|c|c|c|c|c|c|c|c|}
\hline \multirow{2}{*}{ Variables } & \multicolumn{12}{|c|}{ Week of Training } \\
\hline & 1 & 2 & 3 & 4 & 5 & 6 & 7 & 8 & 9 & 10 & 11 & 12 \\
\hline Exercise duration, $\min \mathrm{d}^{-1}$ & 10 & 20 & 35 & 45 & 60 & 60 & 60 & 60 & 60 & 60 & 60 & 60 \\
\hline Treadmill grade $^{a}$ & 15 & 15 & 15 & 15 & 15 & 15 & 15 & 15 & 15 & 15 & 15 & 15 \\
\hline Treadmill speed, $\mathrm{m} \mathrm{min}^{-1}$ & 24 & 24 & 25 & 25 & 26 & 27 & 28 & 29 & 30 & 31 & 32 & 33 \\
\hline
\end{tabular}

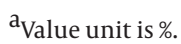


Jafari A et al.

\begin{tabular}{lcc}
\hline Table 2. Primers Used in Real-Time Polymerase Chain Reaction Gene Expression Analysis & \\
\hline Genes & Primer sequence & Product length, bp \\
\hline Bcl2 & F: 5'TATATGGCCCCAGCATGCGA3' & 136 \\
& R:5'GGGCAGGTTTGTCGACCTCA3' & 150 \\
Bax & F: 5'ATCCAAGACCAGGGTGGCTG3' & 138 \\
& R:5'CACAGTCCAAGGCAGTGGGA3' \\
\hline
\end{tabular}

\begin{tabular}{lcc}
\hline $\begin{array}{l}\text { Table 3. Animal Characteristics } \\
\text { a }\end{array}$ & Control $(\mathbf{n}=\mathbf{8})$ & $\begin{array}{c}\text { Exercise training } \\
(\mathbf{n}=\mathbf{8})\end{array}$ \\
\hline $\begin{array}{l}\text { Variables } \\
\text { Body weight, } \mathbf{g}\end{array}$ & $385.25 \pm 29.6$ & $346.22 \pm 22.08$ \\
Heart, $\mathbf{g}$ & $1.06 \pm 0.13$ & $1.11 \pm 0.16$ \\
$\begin{array}{l}\text { Heart/ Body weight, } \\
\text { g/kg }\end{array}$ & $2.77 \pm 0.22$ & $3.22 \pm 0.28$ \\
\hline${ }^{\mathrm{a}}$ Data are presented as mean \pm SD.
\end{tabular}

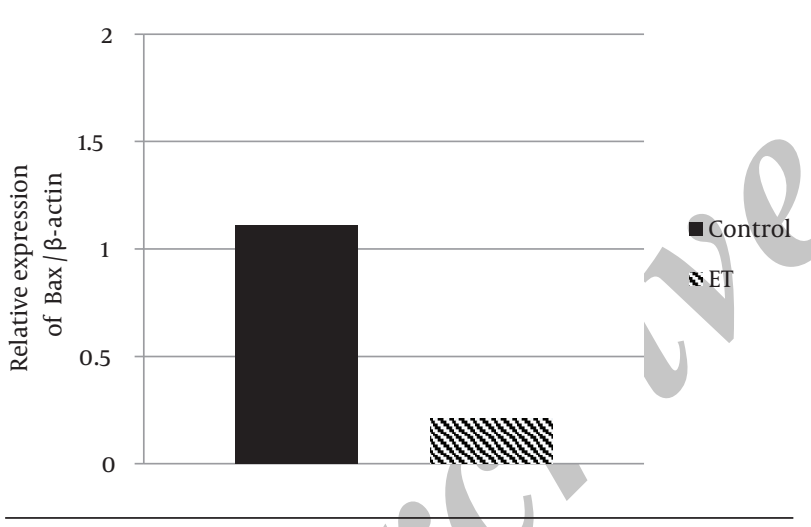

Figure 1. Relative Bax Gene Expression in the Control and Exercise Training Groups

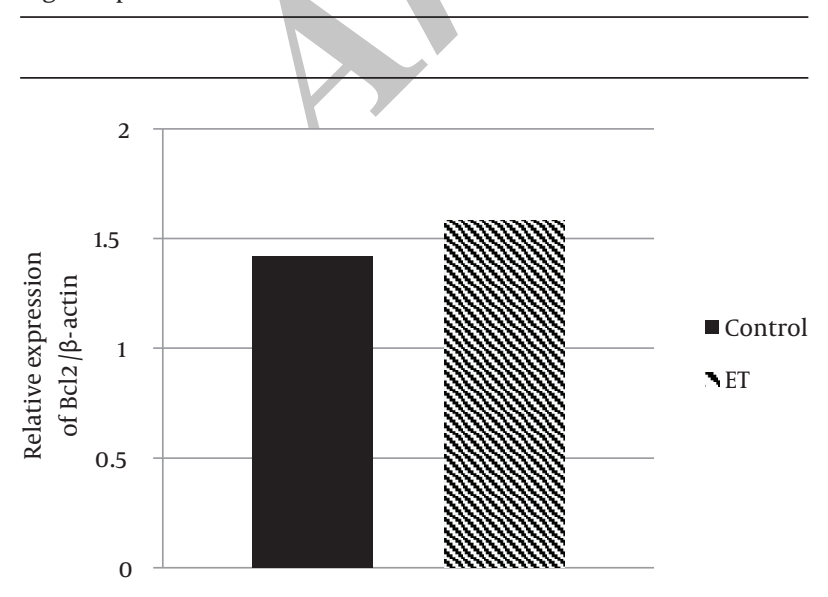

Figure 2. Relative Bcl2 Gene Expression in the Control and Exercise Training Groups

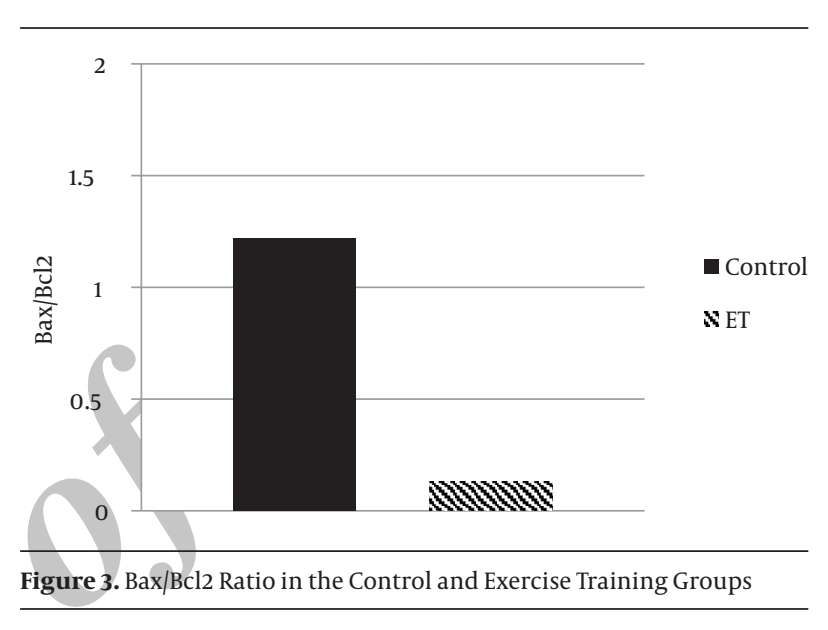

\section{Discussion}

Our results showed that exercise training could decrease body mass in the trained group. Because of energy expenditure by regular exercise training, trained rats showed a decrease of body weight after 12 weeks of training. Exercise training also increased cardiac hypertrophy including heart weight and heart/body weight ratio (15, 16). Moreover, the present study provides evidence regarding the beneficial role of exercise training on apoptosis in postmitotic myocytes. We showed that exercise training attenuates the extent of apoptosis in cardiac tissue when measurements are taken at 48 hours after the last exercise session. The results showed that transcript contents of Bax in ventricle muscles of the trained group were significantly lower than the control group (80\%). Moreover, we found that Bcl-2 protein expression in ventricle muscles of trained animals increased by $11 \%$ when compared with that in the ventricle of control animals, yet this difference did not reach statistical significance. Additionally, the myocardial Bax/Bcl-2 ratio was significantly higher in the control group compared with trained group. The B-cell leukemia/ lymphoma-2 (Bcl-2) families are upstream regulators of apoptosis. The Bcl-2 family members, Bcl-2 associated $\mathrm{X}$ (Bax) protein and $\mathrm{Bcl}-2$, have been identified as putative key proteins involved in the formation of mitochondrial apoptotic channels and also in the regulation of mitochondria permeability and mitochondrial-associated apop- 
totic signaling $(1,2,7)$. The ratio of pro- to anti-apoptotic Bcl-2 family proteins (e.g., Bax/Bcl-2) regulates myonuclei integrity and cell survival by controlling mitochondrial membrane permeability and activation of caspases $(2,12$, 16). The extent for exercise training effects on this family of factors that suppress apoptosis was previously reported by Siu et al. (17). The authors showed a $68 \%$ increase in the Bcl-2 content for animals that were trained by running five days weekly for eight weeks (17). Additionally, Kwak et al. indicated that the Bax/Bcl2 ratio was significantly upregulated with age and markedly reduced by exercise training in the left ventricles (6). Mitochondria appear to play a critical role in regulation of apoptosis in cardiac muscle cells. This includes mobilization of pro-apoptotic proteins to the mitochondrial membrane (e.g. Bax) resulting in a release of mitochondrial-housed factors (e.g. cytosolic cytochrome c; Ref.) to the cytosol and initiation of downstream apoptotic signaling $(7,9)$. The importance of mitochondrial permeability was highlighted in recent work by Fang et al., who showed that blocking the mitochondria permeability pore reduces the degree of apoptosis after myocardial infarction (18). This is consistent with the idea that reduction in Bax or the Bax/Bcl-2 ratio could reduce apoptosis by minimizing mitochondria permeability. Although the mechanism whereby exercise training acts as a countermeasure against myocardial apoptosis has not been fully elucidated, the work by French and coworkers suggests that this may be due, at least in part, to improvements in antioxidant enzyme activity in the myocardium including MnSOD activity (19). This is an important observation that highlights the importance of exercise therapy for improving antioxidant signaling as a means to prevent apoptosis in response to acute myocardial ischemia/reperfusion. Exercise also appears to reduce apoptotic signaling under non-ischemic conditions $(6,17)$ and aging $(6)$, where oxidative stress would be expected to be much less severe than under conditions of ischemia/reperfusion. However, we did not observe significant elevation of Bcl-2 protein expression in the left ventricles of trained young rats when compared to the control rats. Discrepancies between the current study and previous studies could be related to differences in the rats' age and strain used, apex cordis vs. whole left ventricle, and exercise training protocols. It seems that aging hearts are more susceptible to apoptosis than young hearts and that regular exercise training exerts an anti-apoptotic action in aging hearts $(5,6,17)$.

Based upon current findings regarding exercise and apoptosis in the heart, further investigations as future directions, are required to determine the effects of exercise training on the upstream cell protective mechanisms in the heart. For example, exercise training may promote cell survival proteins including Mn isoform of Superoxide Dismutase (MnSOD), NFkB, Extracellular Receptor Kinase (ERK), IGF1/Akt pathway, and Heat Shock Proteins (HSPs) in the heart (20-22), which may be potential upstream regulators of apoptosis. In general, it seems that three-month exercise training was effective in reducing cardiac mitochondrial pro-apoptotic protein. The findings of this study suggest that adopting exercise training as part of a lifelong regimen may provide a more favorable environment to reduce or delay apoptosis in cardiac muscle. However, given the limitations of this study, such as using the TUNEL and Western blot method, more researches are needed to identify effects of exercise trainings on indices of myocardial apoptosis.

\section{Acknowledgments}

The authors would like to thank Dr. Farzam sheykhzadeh and Dr. Amir Monfaredan for all their assistance.

\section{Footnote}

Authors' Contribution:Study concept and design: Afshar Jafari, Hassan Pourrazi, Saeid Nikookheslat and Behzad Baradaran.

\section{References}

1. Favaloro B, Allocati N, Graziano V, Di Ilio C, De Laurenzi V. Role of apoptosis in disease. Aging (Albany NY). 2012;4(5):330-49. [PubMed: 22683550]

2. Kwak HB. Effects of aging and exercise training on apoptosis in the heart. J Exerc Rehabil. 2013;9(2):212-9. doi: 10.12965/jer.130002. [PubMed: 24278863]

3. McMillan EM, Graham DA, Rush JW, Quadrilatero J. Decreased DNA fragmentation and apoptotic signaling in soleus muscle of hypertensive rats following 6 weeks of treadmill training. $J$ Appl Physiol (1985). 2012;113(7):1048-57. doi: 10.1152/japplphysiol.00290.2012. [PubMed:22858629]

4. Whelan RS, Kaplinskiy V, Kitsis RN. Cell death in the pathogenesis of heart disease: mechanisms and significance. Annu Rev Physiol. 2010;72:19-44. doi: 10.1146/annurev.physiol.010908.163111. [PubMed: 20148665]

5. Ko I-G, Kim S-E, Kim C-J, Jee Y-S. Treadmill exercise alleviates aging-induced apoptosis in rat cardiac myocytes. Inter JGerontology. 2013;7(3):152-7. doi: 10.1016/j.ijge.2013.01.001.

6. Kwak HB, Song W, Lawler JM. Exercise training attenuates age-induced changes in apoptotic signaling in rat skeletal muscle. Antioxid Redox Signal.20 06;8(3-4):517-28. doi:10.1089/ars.2006.8.517. [PubMed:16677096]

7. Peterson JM, Bryner RW, Sindler A, Frisbee JC, Alway SE. Mitochondrial apoptotic signaling is elevated in cardiac but not skeletal muscle in the obese Zucker rat and is reduced with aerobic exercise. J Appl Physiol (1985). 2008;105(6):1934-43. doi: 10.1152/japplphysiol.00037.2008. [PubMed: 18832755]

8. Quindry JC, Miller L, McGinnis G, Kliszczewicz B, Irwin JM, Landram M, et al. Ischemia reperfusion injury, KATP channels, and exercise-induced cardioprotection against apoptosis. $J$ Appl Physiol (1985). 2012;113(3):498-506. doi: 10.1152/japplphysiol.00957.2011. [PubMed:22653992]

9. Marin-Garcia J, Goldenthal MJ. Mitochondrial centrality in heart failure. Heart Fail Rev. 2008;13(2):137-50. doi: 10.1007/s10741-0079079-1. [PubMed:18185992]

10. Santana ET, Serra AJ, Silva Junior JA, Bocalini DS, Barauna VG, Krieger JE, Tucci PJF, Serra. Aerobic exercise training induces an anti-apoptotic milieu in myocardial tissue. . Motriz Rio Claro. 2014;20(2):233-8.

11. Lee Y, Min K, Talbert EE, Kavazis AN, Smuder AJ, Willis WT, et al. Exercise protects cardiac mitochondria against ischemia-reperfusion injury. Med Sci Sports Exerc. 2012;44(3):397-405. doi: 10.1249/ MSS.ob013e318231c037. [PubMed:21857373]

12. Vainshtein A, Kazak L, Hood DA. Effects of endurance training on apoptotic susceptibility in striated muscle. J Appl Physiol (1985). 2011;110(6):1638-45. doi: 10.1152/japplphysiol.00020.2011. [PubMed: 21474699] 
13. Xin L, Jian LU,, Wei WU. Effect of Long-term Endurance Exercise on Cardiac Apoptosis. J Mian Nor Univ. 2009:2009-11.

14. Naito H, Powers SK, Demirel HA, Aoki J. Exercise training increases heat shock protein in skeletal muscles of old rats. Med Sci Sports Exerc. 2001;33(5):729-34. [PubMed:11323540]

15. Ellison GM, Waring CD, Vicinanza C, Torella D. Physiological cardiac remodelling in response to endurance exercise training: cellular and molecular mechanisms. Heart. 2012;98(1):5-10. doi: 10.1136/heartjnl-2011-300639. [PubMed:21880653]

16. Huang CC, Lin TJ, Chen CC, Lin WT. Endurance training accelerates exhaustive exercise-induced mitochondrial DNA deletion and apoptosis of left ventricle myocardium in rats. Eur J Appl Physiol. 2009;107(6):697-706. doi: 10.1007/s00421-009-1177-4. [PubMed:19730878]

17. Siu PM, Bryner RW, Martyn JK, Alway SE. Apoptotic adaptations from exercise training in skeletal and cardiac muscles. FASEB J. 2004;18(10):1150-2. doi:10.1096/fj.03-1291fje. [PubMed:15132982]

18. Fang J, Wu L, Chen L. Postconditioning attenuates cardiocyte ultrastructure injury and apoptosis by blocking mitochondrial permeability transition in rats. Acta Cardiol. 2008;63(3):377-87. [PubMed: 18664030]

19. French JP, Hamilton KL, Quindry JC, Lee Y, Upchurch PA, Powers SK. Exercise-induced protection against myocardial apoptosis and necrosis: MnSOD, calcium-handling proteins, and calpain. FASEB J. 2008;22(8):2862-71. doi: 10.1096/fj.07-102541. [PubMed: 18417547]

20. Higashi Y, SukhanovS, Anwar A, Shai SY, Delafontaine P. Aging, atherosclerosis, and IGF-1. J Gerontol A Biol Sci Med Sci.2012;67(6):62639. doi: 10.1093/gerona/gls102. [PubMed: 22491965]

21. Soufi FG, Farajnia S, Aslanabadi N, Ahmadiasl N, Alipour M, Alipour $\mathrm{M}$, et al. Long-term exercise training affects age-induced changes in HSP70 and apoptosis in rat heart. Gen Physiol Biophys. 2008;27(4):263-70. [PubMed: 19202199]

22. Taylor RP, Starnes JW. Age, cell signalling and cardioprotection. Acta Physiol Scand. 2003;178(2):107-16. doi: 10.1046/j.1365201X.2003.01132.x. [PubMed: 12780384]

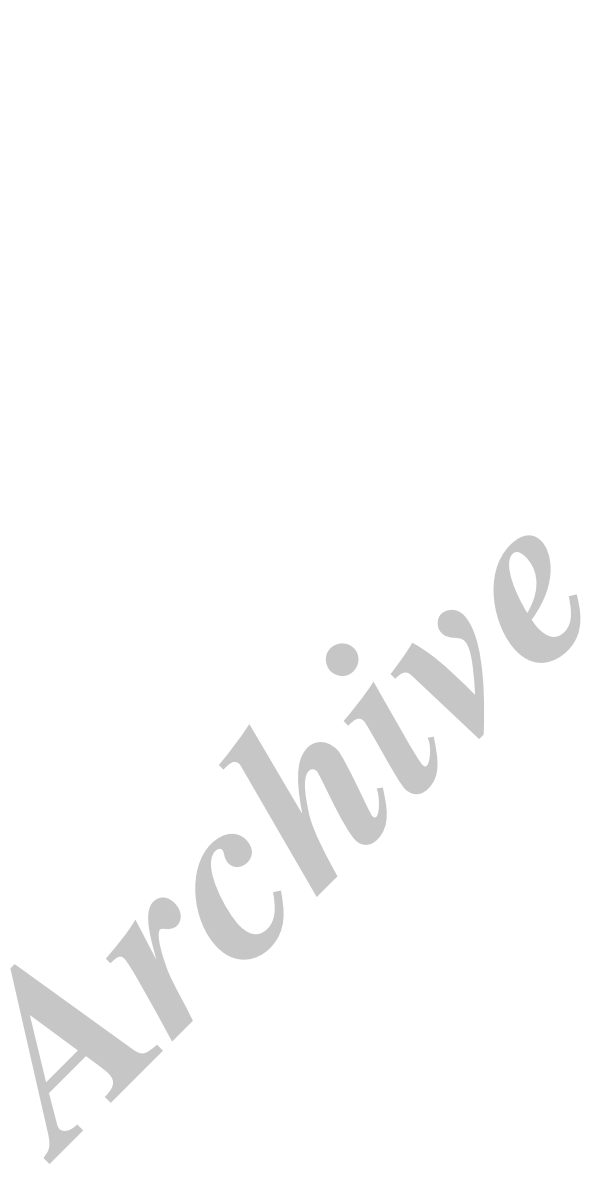

